\title{
Theory-based analysis of clinical efficacy of triptans using receptor occupancy
}

\author{
Kentaro Tokuoka ${ }^{1}$, Risa Takayanagi ${ }^{2}$, Yuji Suzuki $^{3}$, Masayuki Watanabe ${ }^{3}$, Yasuhisa Kitagawa ${ }^{1}$ and Yasuhiko Yamada ${ }^{2 *}$
}

\begin{abstract}
Background: Triptans, serotonin 5-HT $1 \mathrm{~B} / 1 \mathrm{D}$ receptor agonists, exert their action by targeting serotonin 5-HT $1 \mathrm{~B} / 1 \mathrm{D}$ receptors, are used for treatment of migraine attack. Presently, 5 different triptans, namely sumatriptan, zolmitriptan, eletriptan, rizatriptan, and naratriptan, are marketed in Japan. In the present study, we retrospectively analyzed the relationships of clinical efficacy (headache relief) in Japanese and 5- $\mathrm{HT}_{1 \mathrm{~B} / 1 \mathrm{D}}$ receptor occupancy $\left(\Phi_{1 \mathrm{~B}}\right.$ and $\left.\Phi_{1 \mathrm{D}}\right)$. Receptor occupancies were calculated from both the pharmacokinetic and pharmacodynamic data of triptans.

Methods: To evaluate the total amount of exposure to drug, we calculated the area under the plasma concentration-time curve $\left(A \cup C_{C P}\right)$ and the areas under the time curves for $\Phi_{1 \mathrm{~B}}$ and $\Phi_{1 \mathrm{D}}\left(A \cup C_{\Phi}{ }^{1 \mathrm{~B}}\right.$ and $\left.A \cup C_{\Phi}{ }^{1 \mathrm{D}}\right)$. Moreover, parameters expressing drug transfer and binding rates $\left(A_{C p}, A_{\Phi}{ }^{1 B}, A_{\Phi}{ }^{1 D}\right)$ were calculated.

Results: Our calculations showed that $\Phi_{\max }{ }^{1 \mathrm{~B}}$ and $\Phi_{\max }{ }^{1 \mathrm{D}}$ were relatively high at 32.0-89.4\% and 68.4-96.2\%, respectively, suggesting that it is likely that a high occupancy is necessary to attain the clinical effect. In addition, the relationships between therapeutic effect and $A \cup C_{C p}, A \cup C_{\Phi}{ }^{1 B}, A \cup C_{\Phi}{ }^{1 D}$, and $A_{C P} \cdot A \cup C_{C p}$ differed with each drug and administered form, whereas a significant relationship was found between the therapeutic effect and $A_{\Phi}{ }^{1 B} \cdot A \cup C_{\Phi}{ }^{1 B}$ or $A_{\Phi}{ }^{1 D} \cdot A \cup C_{\Phi}{ }^{1 D}$ that was not affected by the drug and the form of administration.

Conclusions: These results suggest that receptor occupancy can be used as a parameter for a common index to evaluate the therapeutic effect. We considered that the present findings provide useful information to support the proper use of triptans.
\end{abstract}

Keywords: Triptans; Serotonin 5-HT $1 \mathrm{~B} / 1 \mathrm{D}$ receptor agonists; Receptor occupancy; Migraine

\section{Background}

Triptans, serotonin $5-\mathrm{HT}_{1 \mathrm{~B} / 1 \mathrm{D}}$ receptor agonists, exert their action by targeting serotonin $5-\mathrm{HT}_{1 \mathrm{~B} / 1 \mathrm{D}}$ receptors, abundantly distributed in cerebral blood vessels, and are used for treatment of migraine attack [1,2]. Presently, 5 different triptans, namely sumatriptan, zolmitriptan, eletriptan, rizatriptan, and naratriptan, are marketed in Japan. Sumatriptan is available as injection, oral, and nasal preparations, while zolmitriptan, eletriptan, rizatriptan, and naratriptan are administered orally. However, differences in their therapeutic effects among individuals and drug characteristics, as well as lack of evidence for selecting a suitable drug for each patient are problems to be resolved [3]. For this reason, it is important to establish an

\footnotetext{
* Correspondence: yamada@ps.toyaku.ac.jp

${ }^{2}$ School of Pharmacy, Tokyo University of Pharmacy and Life Sciences, 1432-1 Horinouchi, Hachioji, Tokyo 192-0392, Japan

Full list of author information is available at the end of the article
}

index for quantitative evaluation of the pharmacological and clinical effects of triptans.

We have been studying the receptor occupancy, which integrates pharmacokinetic and pharmacodynamics data, of a variety of drugs that exert pharmacological effects through receptors, and theoretically evaluated clinical and adverse effects by retrospective analysis [4-7]. Our findings for sumatriptan indicate that receptor binding occupancy could be a useful parameter for clinical evaluation irrespective of the administered form [8]. In the present study, we examined whether our analytical method is applicable to all available triptans.

\section{Methods}

We collected pharmacokinetic and pharmacodynamic parameters from administrations of sumatriptan (injectable, oral and nasal preparations), zolmitriptan (oral preparation), eletriptan (oral preparation), rizatriptan (oral

\section{实}


preparation), and naratriptan (oral preparation) to Japanese patients as well as available clinical efficacy data. In Japan, substantial domestic clinical trial data are included in a new medicine application data package. For the present drugs identified as eligible for analysis, information regarding approved indications, characteristics of the products, and clinical trial data were extracted from review reports downloaded from the website (http://www.info.pmda.go.jp) of the regulatory authority (Pharmaceutical and Medical Devices Agency, PMDA). When information was not provided on this website, we collected data from a relevant published article.

Receptor occupancy following each administration was calculated to investigate its relationship with clinical effect.

\section{Extraction of pharmacokinetic and pharmacodynamic parameters}

As pharmacokinetic parameters, changes in plasma drug concentration following administration $\left(C_{p}\right)$, maximum plasma concentration $\left(\mathrm{C}_{\max }\right)$, time to maximum concentration $\left(\mathrm{T}_{\max }\right)$, plasma unbound fraction value $\left(\mathrm{f}_{\mathrm{u}}\right)$, and the presence of active metabolites were collected from clinical trial data obtained from Japanese subjects. For the pharmacodynamics parameters, the dissociation constant $(\mathrm{Ki})$ values of the serotonin $5-\mathrm{HT}_{1 \mathrm{~B}}$ and $5-\mathrm{HT}_{1 \mathrm{D}}$ receptors were collected.

\section{Extraction of clinical trial data}

To determine clinical effects, changes in values for headache relief rate over time obtained in Phase II and III clinical trials were collected.

Calculation of drug concentration and serotonin $5-\mathrm{HT}_{1 \mathrm{~B} / 1 \mathrm{D}}$ receptor occupancy

Receptor occupancy [ $\Phi(\%)]$ for a particular drug was calculated using (Eq. 1) when the target drug has no active metabolite and only the unchanged drug was the active form, where $C$ is the drug concentration (nM) near the receptor and $K_{i}$ the dissociation constant (nM) from each receptor [9].

$$
\Phi(\%)=\frac{C}{C+K_{i}} \times 100
$$

When only one kind of active metabolite exists, occupancy was calculated using (Eq. 2), where $C_{1}$ and $C_{2}$ are the drug concentrations $(\mathrm{nM})$ of the unchanged drug near the receptor and active metabolite, respectively, and $K_{i 1}$ and $K_{i 2}$ are the receptor dissociation constants (nM) from each receptor of the unchanged drug and active metabolite, respectively [9].

$$
\Phi(\%)=\left\{\frac{\mathrm{C}_{1}}{\mathrm{C}_{1}+\mathrm{K}_{\mathrm{i} 1} \cdot\left(1+\frac{\mathrm{C}_{2}}{\mathrm{~K}_{\mathrm{i} 2}}\right)}+\frac{\mathrm{C}_{2}}{\mathrm{C}_{2}+\mathrm{K}_{\mathrm{i} 2} \cdot\left(1+\frac{\mathrm{C}_{1}}{\mathrm{~K}_{\mathrm{i} 1}}\right)}\right\}
$$

If the unbound drug in plasma is speculated to simply diffuse through the vascular wall to reach the intercellular gap and reach instant equilibrium, the drug concentration near the receptor, $C$, can be approximated based on the plasma unbound drug concentration $\left(C_{f}\right)$ obtained by multiplying the plasma drug concentration $\left(C_{p}\right)$ by the plasma unbound fraction $\left(f_{u}\right): C_{f}=C_{p} \times f_{u}(n M)$. Furthermore, by using the $5-\mathrm{HT}_{1 \mathrm{~B}}$ and $5-\mathrm{HT}_{1 \mathrm{D}}$ receptor dissociation constants $\left(K_{i}^{1 B}, K_{i}^{1 D}\right)$, the occupancy for each subtype, $\Phi_{1 \mathrm{~B}}$ and $\Phi_{1 \mathrm{D}}$, was calculated. On the basis of data reported regarding the time course of plasma concentration after administration of each drug in Japanese subjects, the plasma unbound drug concentration $\left(C_{f}\right)$ was calculated. Then, $\Phi_{1 \mathrm{~B}}$ and $\Phi_{1 \mathrm{D}}$ were calculated using Eq. 1 or Eq. 2 to examine changes over time.

\section{Calculation of total amount of exposure to drug and serotonin $5-\mathrm{HT}_{1 \mathrm{~B} / 1 \mathrm{D}}$ receptor occupancy}

The area under the plasma concentration-time curve $\left(\mathrm{AUC}_{\mathrm{CP}}\right)$ and the areas under the time curves for $\Phi_{1 \mathrm{~B}}$ and $\Phi_{1 \mathrm{D}}\left(\mathrm{AUC}_{\Phi}{ }^{1 \mathrm{~B}}\right.$ and $\left.\mathrm{AUC}_{\Phi}{ }^{1 \mathrm{D}}\right)$ from the start of drug administration to the time of evaluating headache relief [t (hr)] were calculated using the trapezoidal method.

\section{Calculation of systemic drug transfer and serotonin $5-\mathrm{HT}_{1 \mathrm{~B} / 1 \mathrm{D}}$ receptor binding rates}

It has been suggested that the onset of the effect of triptans is related to the systemic drug-transfer rate [10], thus parameters expressing drug transfer and binding rates $\left(A_{c p}, A_{\Phi}{ }^{1 B}, A_{\Phi}{ }^{1 D}\right)$ were calculated by using (Eq. 3, 4, 5), where the maximum plasma concentration was $C_{\max }$, and the time to maximum concentration $\mathrm{T}_{\max }$ and the maximum occupancy were $\Phi_{\max }^{1 \mathrm{~B}}$ and $\Phi_{\max }{ }^{1 \mathrm{D}}$, respectively.

$$
\begin{aligned}
& A_{c p}=\mathrm{C}_{\max } / \mathrm{T}_{\max } \\
& A_{\Phi}{ }^{1 B}=\Phi_{\max }^{1 \mathrm{~B}} / \mathrm{T}_{\max } \\
& A_{\Phi}{ }^{1 D}=\Phi_{\max }^{1 \mathrm{D}} / \mathrm{T}_{\max }
\end{aligned}
$$

Analysis of relationship between parameters for receptor occupancy and clinical effects of each drug following administration

The relationship of each parameter, obtained as noted in Section 2, with clinical effects was examined. We initially investigated the relationship of $\mathrm{AUC}_{\mathrm{Cp}}, \mathrm{AUC}_{\Phi}{ }^{1 \mathrm{~B}}$, and $\mathrm{AUC}_{\Phi}{ }^{1 \mathrm{D}}$ with headache relief rate at each evaluation time point. Then, $A_{c p} \cdot \mathrm{AUC}_{\mathrm{cp}}, A_{\Phi}{ }^{1 B} \cdot \mathrm{AUC}_{\Phi}{ }^{1 \mathrm{~B}}$, and $A_{\Phi}{ }^{1 D} \cdot \mathrm{AUC}_{\Phi}{ }^{1 \mathrm{D}}$, 
Table 1 The various parameters for Triptans marketed in Japan [11-20]

\begin{tabular}{|c|c|c|c|c|c|c|}
\hline Drugs & $\begin{array}{l}\text { Administration route } \\
\text { (dosage form) }\end{array}$ & $\begin{array}{l}\text { Standard dose } \\
\text { in Japan (mg) }\end{array}$ & $\mathrm{MW}(\mathrm{g} / \mathrm{mol})$ & $\begin{array}{l}\text { Plasma unbound } \\
\text { fraction; fu }\end{array}$ & $\mathrm{Ki}^{1 \mathrm{~B} *}(\mathrm{nM})$ & $\mathrm{Ki}^{1 \mathrm{D} *}(\mathrm{nM})$ \\
\hline \multirow[t]{3}{*}{ Sumatriptan [11-13] } & SC & 3 & 295.41 & 0.66 & 12.6 & 12.6 \\
\hline & $\mathrm{PO}$ & 50 & & & & \\
\hline & NS & 20 & & & & \\
\hline \multirow[t]{4}{*}{ Zolmitriptan [14-16] } & $\mathrm{PO}$ & 2.5 & [unchanged drug] & [unchanged drug] & [unchanged drug] & [unchanged drug] \\
\hline & ODT & & 287.30 & 0.8 & 6.31 & 2.51 \\
\hline & & & [active metabolite] & [active metabolite] & [active metabolite] & [active metabolite] \\
\hline & & & 273.36 & 0.75 & 1.58 & 0.5 \\
\hline Eletriptan [17] & $\mathrm{PO}$ & 20 & 382.52 & 0.13 & 10.0 & 1.2 \\
\hline \multirow[t]{2}{*}{ Rizatriptan $[18,19]$} & $\mathrm{PO}$ & 10 & 269.35 & 0.86 & 138 & 13.1 \\
\hline & ODT & & & & & \\
\hline Naratriptan [20] & $\mathrm{PO}$ & 2.5 & 335.47 & 0.71 & 2.2 & 2.3 \\
\hline
\end{tabular}

${ }^{*}$ calculated from pKi or $\mathrm{plC}_{50}$.

SC: subcutaneous injection.

PO: oral tablet.

NS: nasal spray.

ODT: orally disintegrating tablet.

$\mathrm{Ki}_{1 \mathrm{~B}}: 5-\mathrm{HT}_{1 \mathrm{~B}}$ receptor dissociation constant.

$\mathrm{Ki}_{1 \mathrm{D}}: 5-\mathrm{HT}_{1 \mathrm{D}}$ receptor dissociation constant.

Table 2 Time courses for headache relief (percent of patients (\%)) in Japanese subjects [11,16,21-27]

\begin{tabular}{|c|c|c|c|c|c|c|c|c|c|}
\hline t (Time after administration) (hr) & 0.17 & 0.25 & 0.5 & 0.75 & 1 & 1.5 & 2 & 3 & 4 \\
\hline \multicolumn{10}{|l|}{ Sumatriptan $[11,21,22]$} \\
\hline SC $3 \mathrm{mg} *$ & 30.3 & $37.0-63.3$ & $62.0-81.8$ & 73.7 & 78.9-93.9 & - & - & - & - \\
\hline SC 6 mg & - & 71.4 & 71.4 & - & 85.7 & - & - & - & - \\
\hline \multicolumn{10}{|l|}{ Sumatriptan [23] } \\
\hline PO 50 mg ※ & - & - & 7 & - & 32 & - & 41 & 63 & 68 \\
\hline PO 100 mg & - & - & 10 & - & 29 & - & 55 & 65 & 68 \\
\hline \multicolumn{10}{|l|}{ Sumatriptan [24] } \\
\hline NS 10 mg & - & - & 19.3 & - & 33.3 & - & 58.9 & - & 62.5 \\
\hline NS 20 mg $\%$ & - & - & $15.7-27.8$ & - & $31.5-56.4$ & 49.1 & $63.0-70.9$ & - & 73.2 \\
\hline \multicolumn{10}{|l|}{ Zolmitriptan [16] } \\
\hline PO 2.5 mg ※ & - & - & 9.8 & - & 28.3 & - & 55.6 & - & 76.5 \\
\hline \multicolumn{10}{|l|}{ Eletriptan [25] } \\
\hline PO 20 mg ※ & - & - & 13 & - & 37 & - & 64 & - & 86 \\
\hline PO 40 mg & - & - & 12 & - & 33 & - & 67 & - & 88 \\
\hline \multicolumn{10}{|l|}{ Rizatriptan [26] } \\
\hline PO 10 mg ※ & - & - & 10.1 & - & 26.1 & 50.7 & 59.4 & - & - \\
\hline \multicolumn{10}{|l|}{ Naratriptan [27] } \\
\hline PO 1 mg & - & - & - & - & 21.2 & - & 41.3 & 60.6 & 71.2 \\
\hline PO 2.5 mg ※ & - & - & - & - & 15.6 & - & 50.5 & 71.6 & 77.1 \\
\hline
\end{tabular}

※: standard dose in Japan.

SC: subcutaneous injection.

PO: oral tablet.

NS: nasal spray. 
which represented the AUC values multiplied, respectively, by $A_{c p}, A_{\Phi}{ }^{1 B}$, and $A_{\Phi}{ }^{1 D}$ obtained with the equations, Eq. 3, Eq. 4, and Eq. 5, and coupled with the rate were calculated for evaluating the relationship with headache relief rate. When an association was found between a parameter and headache relief rate, analysis was conducted by using the sigmoid Emax model shown in Eq. 6, where E is headache relief rate (\%), $\mathrm{E}_{\max }$ the maximum headache relief rate (\%), $\mathrm{X}$ the parameters with a favorable relationship with headache relief rate, $\mathrm{EC}_{50}$ the value of $\mathrm{X}$ when $\mathrm{E}_{\max }$ was $50 \%$, and $\gamma$ the Hill coefficient. The relationship between $X$ and headache relief rate $(\mathrm{E})$ was analyzed using a nonlinear least squares method to calculate $\mathrm{E}_{\max }, \mathrm{EC}_{50}$, and $\gamma$. For the analyses, we used the MLAB software package (Civilized Software Inc.).

$$
\mathrm{E}=\mathrm{E}_{\max } \cdot \mathrm{X}^{\gamma} /\left(\mathrm{EC}_{50}+\mathrm{X}^{\gamma}\right)
$$

\section{Results}

\section{Extraction of pharmacokinetic and pharmacodynamic} parameters

The various parameters collected for each drug are shown in Table 1.

For pharmacodynamic parameters, the value of $\mathrm{K}_{\mathrm{i}}$ was calculated on the basis of the reported values for $\mathrm{pK}_{\mathrm{i}}$ and $\mathrm{pIC}_{50}$ of the $5-\mathrm{HT}_{1 \mathrm{~B}}$ and $5-\mathrm{HT}_{1 \mathrm{D}}$ receptors. Sumatriptan and naratriptan showed nearly the same levels for those receptors, while zolmitriptan (unchanged drug and active metabolite), eletriptan, and rizatriptan tended to show a higher affinity for $5-\mathrm{HT}_{1 \mathrm{D}}$ than $5-\mathrm{HT}_{1 \mathrm{~B}}$.

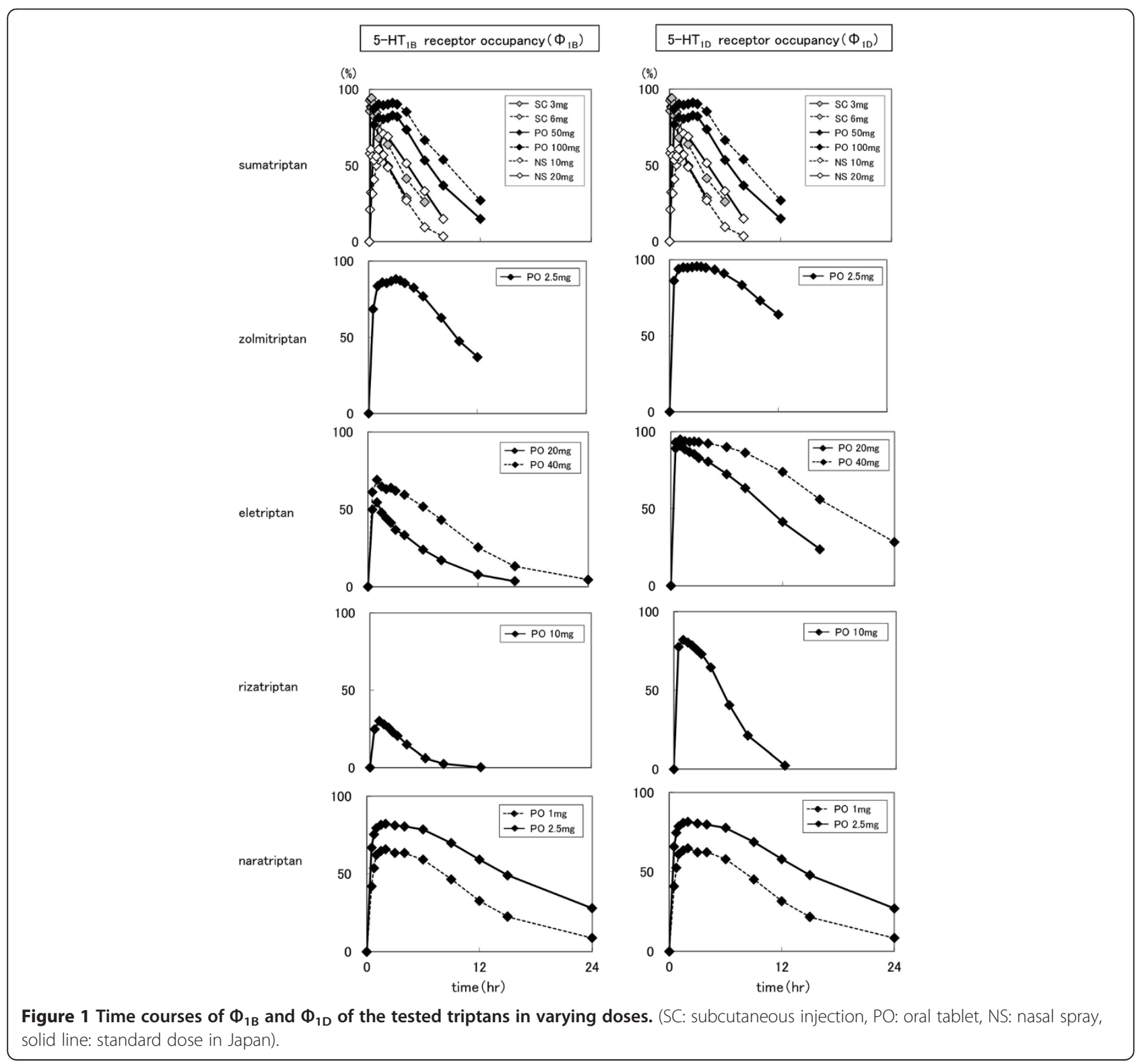


Table 3 Calculated (1) $A U C_{c p}$, (2) $A U C_{\Phi}{ }^{1 B}$, and (3) $A U C_{\Phi}{ }^{1 D}$ values

\begin{tabular}{|c|c|c|c|c|c|c|c|c|c|}
\hline t (Time after administration) (hr) & 0.17 & 0.25 & 0.5 & 0.75 & 1 & 1.5 & 2 & 3 & 4 \\
\hline \multicolumn{10}{|l|}{ (1) $A U C_{c p}(n g \cdot h r / m L)$} \\
\hline \multicolumn{10}{|l|}{ Sumatriptan } \\
\hline SC 3 mg* & 4.9 & 8.3 & 17.0 & 22.6 & 26.4 & - & - & - & - \\
\hline SC 6 mg & - & 17.0 & 34.8 & - & 51.9 & - & - & - & - \\
\hline \multicolumn{10}{|l|}{ Sumatriptan } \\
\hline PO $50 \mathrm{mg}$ ※ & - & - & 4.7 & - & 15.7 & - & 40.0 & 66.4 & 87.4 \\
\hline PO 100 mg & - & - & 9.7 & - & 32.6 & - & 83.3 & 138.6 & 181.6 \\
\hline \multicolumn{10}{|l|}{ Sumatriptan } \\
\hline NS 10 mg & - & - & 1.2 & - & 4.0 & - & 10.7 & - & 18.2 \\
\hline NS 20 mg ※ & - & - & 3.5 & - & 7.2 & 12.8 & 19.4 & - & 38.0 \\
\hline \multicolumn{10}{|l|}{ Zolmitriptan } \\
\hline PO 2.5 mg ※ & - & - & 0.51 & - & 1.87 & - & 5.4 & - & 11.3 \\
\hline \multicolumn{10}{|l|}{ Eletriptan } \\
\hline PO 20 mg ※ & - & - & 7.7 & - & 25.2 & - & 56.9 & - & 99.2 \\
\hline PO 40 mg & - & - & 12.4 & - & 43.0 & - & 105.9 & - & 214.1 \\
\hline \multicolumn{10}{|l|}{ Rizatriptan } \\
\hline PO $10 \mathrm{mg}$ ※ & - & - & 3.6 & - & 11.8 & 20.6 & 28.5 & - & - \\
\hline \multicolumn{10}{|l|}{ Naratriptan } \\
\hline PO 1 mg & - & - & - & - & 0.8 & - & 2.7 & 4.6 & 6.4 \\
\hline PO 2.5 mg ※ & - & - & - & - & 2.1 & - & 6.6 & 11.2 & 15.6 \\
\hline \multicolumn{10}{|l|}{ (2) $A \cup C_{\Phi}{ }^{1 B}(\% \cdot h r)$} \\
\hline \multicolumn{10}{|l|}{ Sumatriptan } \\
\hline SC $3 \mathrm{mg} *$ & 11.3 & 18.3 & 39.7 & 59.6 & 77.7 & - & - & - & - \\
\hline SC 6 mg & - & 19.6 & 42.7 & - & 85.0 & - & - & - & - \\
\hline \multicolumn{10}{|l|}{ Sumatriptan } \\
\hline PO 50 mg ※ & - & - & 19.3 & - & 58.9 & - & 140.0 & 222.5 & 300.4 \\
\hline PO 100 mg & - & - & 21.8 & - & 66.3 & - & 156.2 & 247.0 & 334.9 \\
\hline \multicolumn{10}{|l|}{ Sumatriptan } \\
\hline NS 10 mg & - & - & 14.5 & - & 38.9 & - & 93.2 & - & 169.2 \\
\hline NS 20 mg* & - & - & 26.3 & - & 54.6 & 87.5 & 122.6 & - & 243.2 \\
\hline \multicolumn{10}{|l|}{ Zolmitriptan } \\
\hline PO 2.5 mg* & - & - & 17.1 & - & 55.2 & - & 140.7 & - & 314.9 \\
\hline \multicolumn{10}{|l|}{ Eletriptan } \\
\hline PO 20 mg* & - & - & 12.5 & - & 38.6 & - & 87.3 & - & 163.2 \\
\hline PO 40 mg & - & - & 15.3 & - & 47.9 & - & 113.3 & - & 237.2 \\
\hline \multicolumn{10}{|l|}{ Rizatriptan } \\
\hline PO $10 \mathrm{mg}$ ※ & - & - & 6.2 & - & 19.9 & 34.4 & 47.8 & - & - \\
\hline \multicolumn{10}{|l|}{ Naratriptan } \\
\hline PO 1 mg & - & - & - & - & 36.9 & - & 101.2 & 165.7 & 229.1 \\
\hline PO $2.5 \mathrm{mg}{ }^{※}$ & - & - & - & - & 53.9 & - & 135.1 & 216.7 & 297.6 \\
\hline \multicolumn{10}{|l|}{ (3) $A \cup C_{\Phi}{ }^{1 D}(\% \cdot h r)$} \\
\hline \multicolumn{10}{|l|}{ Sumatriptan } \\
\hline SC 3 mg $\%$ & 11.3 & 18.3 & 39.7 & 59.6 & 77.7 & - & - & - & - \\
\hline SC 6 mg & - & 19.6 & 42.7 & - & 85.0 & - & - & - & - \\
\hline
\end{tabular}


Table 3 Calculated (1) AUC ${ }_{\mathrm{cp}}$ (2) $\mathrm{AUC}_{\Phi}{ }^{1 \mathrm{~B}}$, and (3) AUC ${ }_{\Phi}{ }^{1 \mathrm{D}}$ values (Continued)

\begin{tabular}{|c|c|c|c|c|c|c|c|c|c|}
\hline \multicolumn{10}{|l|}{ Sumatriptan } \\
\hline PO 50 mg $\%$ & - & - & 19.3 & - & 58.9 & - & 140.0 & 222.5 & 300.4 \\
\hline PO 100 mg & - & - & 21.8 & - & 66.3 & - & 156.2 & 247.0 & 334.9 \\
\hline \multicolumn{10}{|l|}{ Sumatriptan } \\
\hline NS 10 mg & - & - & 14.5 & - & 38.9 & - & 93.2 & - & 169.2 \\
\hline NS 20 mg ※ & - & - & 26.3 & - & 54.6 & 87.5 & 122.6 & - & 243.2 \\
\hline \multicolumn{10}{|l|}{ Zolmitriptan } \\
\hline PO 2.5 mg ※ & - & - & 21.6 & - & 66.6 & - & 161.2 & - & 351.8 \\
\hline \multicolumn{10}{|l|}{ Eletriptan } \\
\hline PO 20 mg ※ & - & - & 22.3 & - & 67.4 & - & 156.0 & - & 322.9 \\
\hline PO 40 mg & - & - & 23.2 & - & 70.2 & - & 164.2 & - & 350.5 \\
\hline \multicolumn{10}{|l|}{ Rizatriptan } \\
\hline PO 10 mg ※ & - & - & 19.4 & - & 59.3 & 99.8 & 139.5 & - & - \\
\hline \multicolumn{10}{|l|}{ Naratriptan } \\
\hline PO 1 mg & - & - & - & - & 36.9 & - & 101.2 & 165.7 & 229.1 \\
\hline PO 2.5 mg ※ & - & - & - & - & 53.9 & - & 135.1 & 216.7 & 297.6 \\
\hline
\end{tabular}

※: standard dose in Japan.

SC: subcutaneous injection.

PO: oral tablet.

NS: nasal spray.

\section{Extraction of clinical trial data}

Table 2 shows reported time courses for headache relief rate in Japanese subjects given each drug at various doses in clinical trial settings.

The sumatriptan injectable preparation showed a high level of headache relief from the initial stage of administration, with $60 \%$ or greater at 0.5 hours and $80 \%$ or more at 1 hour after administration. Moreover, the sumatriptan nasal preparation tended to exert its effect earlier than the other drugs. However, a relief rate of about $60-88 \%$ was attained from 2 hours with these drugs and preparations.

\section{Calculation of serotonin $5-\mathrm{HT}_{1 \mathrm{~B} / 1 \mathrm{D}}$ receptor occupancy at} time of administration of each drug

The time courses of $\Phi_{1 \mathrm{~B}}$ and $\Phi_{1 \mathrm{D}}$ calculated on the basis of changes in plasma concentration after administration of the tested triptans in varying doses [11,16,23-27] demonstrated different aspects depending on the drug and dosage form (Figure 1).

Sumatriptan and naratriptan showed nearly the same transition for the $5-\mathrm{HT}_{1 \mathrm{~B}}$ and $5-\mathrm{HT}_{1 \mathrm{D}}$ receptors, while zolmitriptan, eletriptan, and rizatriptan showed higher $\Phi$ values for the $5 \mathrm{HT}_{1 \mathrm{D}}$ receptor than the $5-\mathrm{HT}_{1 \mathrm{~B}}$ receptor.

\section{Calculation of total amount of exposure to drug and serotonin $5-\mathrm{HT}_{1 \mathrm{~B} / 1 \mathrm{D}}$ receptor occupancy}

Table 3 shows the $\mathrm{AUC}_{\mathrm{cp}}, \mathrm{AUC}_{\Phi}{ }^{1 \mathrm{~B}}$, and $\mathrm{AUC}_{\Phi}{ }^{1 \mathrm{D}}$ values from the time of administration until each evaluation time when headache relief rate was determined by the trapezoidal method.

\section{Calculation of systemic drug-transfer rate and rate of} serotonin $5-\mathrm{HT}_{1 \mathrm{~B} / 1 \mathrm{D}}$ receptor binding

Table 4 shows calculated values for $\mathrm{T}_{\max }, \mathrm{C}_{\max }$, the absorption rate-related parameters $A_{c p}\left(\mathrm{C}_{\max } / \mathrm{T}_{\max }\right), \Phi_{\max }{ }^{1 \mathrm{~B}}$, $\Phi_{\max }{ }^{1 \mathrm{D}}$, and the receptor occupancy rate-related parameters $A_{\Phi}{ }^{1 B}\left(\Phi_{\max }{ }^{1 \mathrm{~B}} / \mathrm{T}_{\max }\right)$ and $A_{\Phi}{ }^{1 D}\left(\Phi_{\max }{ }^{1 \mathrm{D}} / \mathrm{T}_{\max }\right)$.

For $\mathrm{T}_{\max }$, the sumatriptan injectable preparation was the fastest at about 0.2 hours, followed by the nasal preparation at about 1 hour and the tablet at about 1-3 hours. As for $\Phi, \Phi_{\max }^{1 \mathrm{~B}}$ at the standard dose of each drug ranged from $32.0-89.4 \%$, while $\Phi_{\max }{ }^{1 \mathrm{D}}$ ranged from 68.4-96.2\%.

\section{Analyses of relationships between parameters for receptor occupancy and clinical effects at the time of} administration of each drug

We examined the relationships between the parameters obtained as noted in Section 2 above and clinical effects. As for that between $\mathrm{AUC}_{\mathrm{cp}}$ and headache relief rate, relief rate increased along with $\mathrm{AUC}_{\mathrm{cp}}$ increases. However, that relationship tended to vary among the tested drugs (Figure 2).

For the relationship of $\mathrm{AUC}_{\Phi}{ }^{1 \mathrm{~B}}$ and $\mathrm{AUC}_{\Phi}{ }^{1 \mathrm{D}}$ with headache relief rate, the elevation of both was related to increased headache relief rate, with different tendencies depending on the drug. We also found that a relationship with $5-\mathrm{HT}_{1 \mathrm{D}}$ receptors was likely for the oral preparations irrespective of drug, while the injectable and nasal preparations showed different aspects (Figure 3). 
Table 4 Pharmacokinetic parameters and calculated values [11,16,23-27]

\begin{tabular}{|c|c|c|c|c|c|c|c|}
\hline & $\begin{array}{l}T_{\max } \\
(\mathrm{hr})\end{array}$ & $\begin{array}{l}C_{\max } \\
(\mathrm{ng} / \mathrm{mL})\end{array}$ & $\begin{array}{l}A_{c p}{ }^{*} \\
\left(C_{\max } / T_{\max }\right)\end{array}$ & $\begin{array}{l}\Phi_{\max }^{1 B} * \\
(\%)\end{array}$ & $\begin{array}{l}\Phi_{\max }{ }^{1 D} * \\
(\%)\end{array}$ & $\begin{array}{l}A_{\Phi}^{1 B *} \\
\left(\Phi_{\max 1 \mathrm{~B}} / \mathrm{T}_{\max }\right)\end{array}$ & $\begin{array}{l}A_{\Phi}^{1 D *} \\
\left(\Phi_{\max 1 \mathrm{D}} / \mathrm{T}_{\max }\right)\end{array}$ \\
\hline \multicolumn{8}{|c|}{ Sumatriptan [11] } \\
\hline SC 3 mg ${ }^{*}$ & 0.21 & 44 & 209.52 & 88.6 & 88.6 & 422.09 & 422.09 \\
\hline SC $6 \mathrm{mg}$ & 0.2 & 95.5 & 477.50 & 94.4 & 94.4 & 472.12 & 472.12 \\
\hline \multicolumn{8}{|c|}{ Sumatriptan [23] } \\
\hline PO 50 mg $※$ & 1.8 & 32.6 & 18.11 & 85.3 & 85.3 & 47.36 & 47.36 \\
\hline PO 100 mg & 2 & 58.2 & 29.10 & 91.2 & 91.2 & 45.58 & 45.58 \\
\hline \multicolumn{8}{|c|}{ Sumatriptan [24] } \\
\hline NS 10 mg & 1.1 & 6.4 & 5.82 & 53.2 & 53.2 & 48.33 & 48.33 \\
\hline NS 20 mg* & 1.3 & 12.2 & 9.38 & 68.4 & 68.4 & 52.61 & 52.61 \\
\hline \multicolumn{8}{|c|}{ Zolmitriptan [16] } \\
\hline \multirow[t]{4}{*}{ PO $2.5 \mathrm{mg}$ ※ } & [unchanged drug] & [unchanged drug] & [unchanged drug] & 89.4 & 96.2 & 26.79 & 32.1 \\
\hline & 3 & 5.23 & 1.74 & & & & \\
\hline & [active metabolite] & [active metabolite] & [active metabolite] & & & & \\
\hline & 3 & 3.5 & 1.17 & & & & \\
\hline \multicolumn{8}{|l|}{ Eletriptan [25] } \\
\hline PO 20 mg ※ & 1 & 38.9 & 38.90 & 56.9 & 91.7 & 56.93 & 91.7 \\
\hline PO 40 mg & 1.2 & 69.7 & 58.08 & 70.3 & 95.2 & 58.6 & 79.3 \\
\hline \multicolumn{8}{|c|}{ Rizatriptan [26] } \\
\hline PO 10 mg $\%$ & 1 & 20.3 & 20.30 & 32.0 & 83.2 & 32.0 & 83.2 \\
\hline \multicolumn{8}{|c|}{ Naratriptan [27] } \\
\hline PO 1 mg & 2.17 & 2.12 & 0.98 & 67.1 & 66.1 & 30.9 & 30.5 \\
\hline PO $2.5 \mathrm{mg}$ * & 2.68 & 5.62 & 2.10 & 84.4 & 83.8 & 31.5 & 31.3 \\
\hline
\end{tabular}

*: calculated, ※: standard dose in Japan.

SC: subcutaneous injection.

PO: oral tablet.

NS: nasal spray.

$T_{\max }$ : time to $C_{\max }$.

$C_{\text {max }}$ : peak plasma concentration.

$\Phi_{\max }{ }^{1 \mathrm{~B}}$ : peak $\Phi_{1 \mathrm{~B}}$.

$\Phi_{\max }{ }^{1 D}$ : peak $\Phi_{1 \mathrm{D}}$.

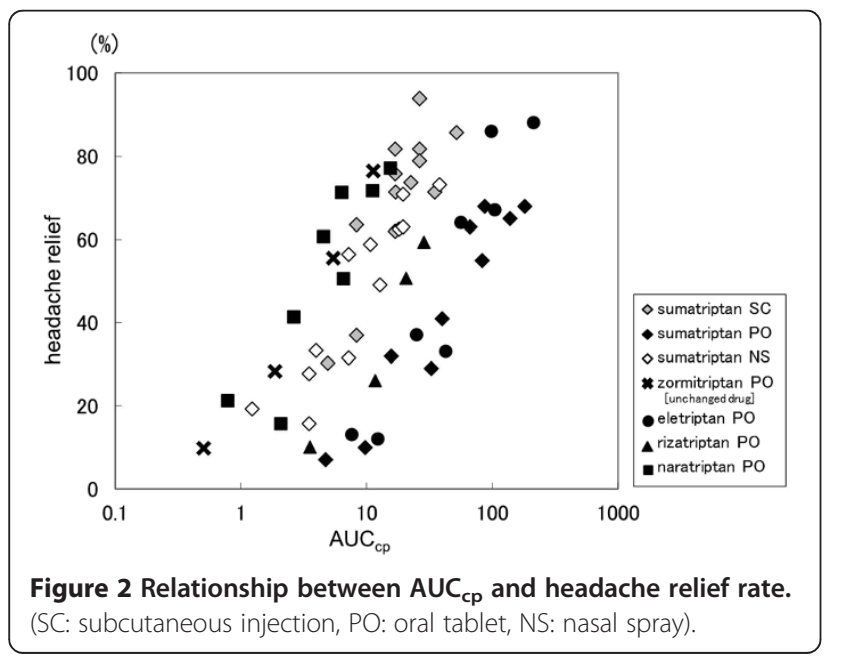

Figure 4 shows the relationship between $\mathrm{AUC}_{\mathrm{cp}}$ $\left(A_{c p} \cdot \mathrm{AUC}_{\mathrm{cp}}\right)$, in which the value for plasma drug concentration-related $A_{c p}$ was coupled with velocity, and headache relief rate.

In the analysis using $A_{c p} \cdot \mathrm{AUC}_{\mathrm{cp}}$, headache relief rate was increased along with the increase in $\mathrm{A}_{c p} \cdot \mathrm{AUC}_{\mathrm{cp}}$. However, the relationship varied depending on the drug. Meanwhile, the relationship between $\mathrm{AUC}_{\Phi}\left(A_{\Phi}{ }^{1 B}\right.$. $\mathrm{AUC}_{\Phi}{ }^{1 \mathrm{~B}}$ and $\left.A_{\Phi}{ }^{1 D} \cdot \mathrm{AUC}_{\Phi}{ }^{1 \mathrm{D}}\right)$, in which receptor occupancy-related $A_{\Phi}$ was coupled with velocity, was likely to be assimilated into a single line.

As a result of our analysis using the sigmoid $E_{\max }$ model, the fitted curve of our model corresponded well to the actual measurement value (Figure 5). The correlation coefficient was 0.90 for the $5-\mathrm{HT}_{1 \mathrm{~B}}$ receptor and 0.92 for the $5-\mathrm{HT}_{1 \mathrm{D}}$ receptor. The parameters obtained are shown in Table 5. 

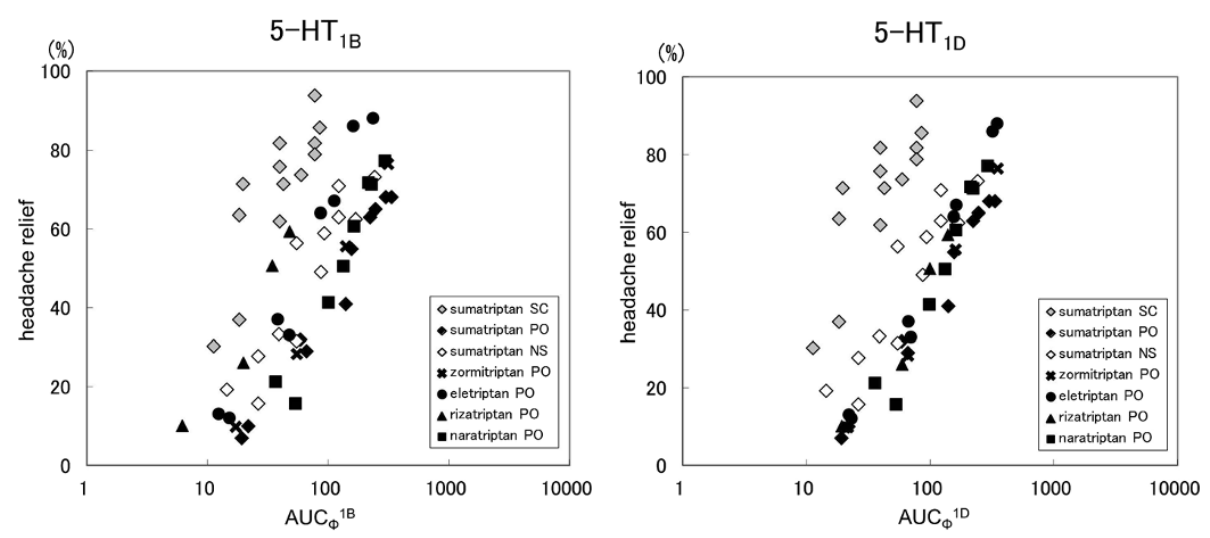

Figure 3 Relationships between $\mathrm{AUC}_{\Phi}{ }^{1 \mathrm{~B}}$ or $\mathrm{AUC}_{\Phi}{ }^{1 \mathrm{D}}$ and headache relief rate. (SC: subcutaneous injection, PO: oral tablet, NS: nasal spray).

Both $A_{\Phi}^{1 B} \cdot \mathrm{AUC}_{\Phi}^{1 \mathrm{~B}}$ and $A_{\Phi}{ }^{1 D} \cdot \mathrm{AUC}_{\Phi}{ }^{1 \mathrm{D}}$ could be assimilated into a single line irrespective of drug kind and dosage form, though the correlation was higher for the $5-\mathrm{HT}_{1 \mathrm{D}}$ receptor than the $5-\mathrm{HT}_{1 \mathrm{~B}}$ receptor.

\section{Discussion}

In our previous study, as an attempt to establish information for the optimal use of triptans, we focused on sumatriptan, which has multiple drug formulations available [8]. Our results clarified that the parameter $A_{\Phi} \cdot \mathrm{AUC}_{\Phi}$, in which the receptor binding occupancy of the action target, the $5-\mathrm{HT}_{1 \mathrm{~B} / 1 \mathrm{D}}$ receptor, and occupancy rate were taken into account, was a good index for quantitatively evaluating clinical efficacy without regard to dosage form. In the present study, for the purpose of evaluating whether our method is applicable for analysis of triptans in general, we examined values obtained when various triptan preparations were administered to Japanese subjects.

In principle, the pharmacokinetic data were collected from clinical trial data obtained from Japanese subjects.

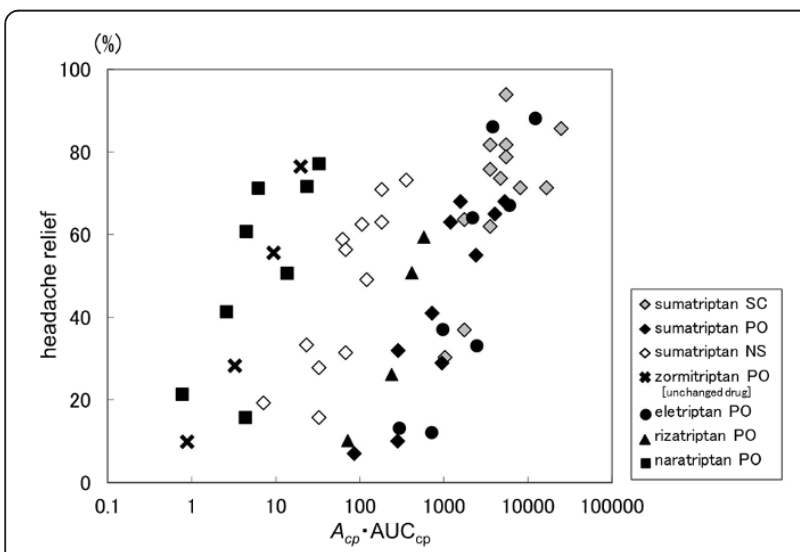

Figure 4 Relationship between $A_{C P} \cdot A U C_{C P}$ and headache relief rate. (SC: subcutaneous injection, $\mathrm{PO}$ : oral tablet, NS: nasal spray).
For zolmitriptan, the presence of an active metabolite, which contributes to drug efficacy, was taken into account in the analysis. Moreover, for eletriptan and rizatriptan, the presence of an active metabolite was not taken into account, as its contribution to efficacy is reported to be low.

For the pharmacodynamic data, the value of $K_{i}$, which represents affinity for the $5-\mathrm{HT}_{1 \mathrm{~B}}$ and $5-\mathrm{HT}_{1 \mathrm{D}}$ receptors, was investigated. Generally, it is desirable to use data measured simultaneously in identical experimental systems. However, since no such data were available, we used values previously reported for each drug. More precise analysis might be achieved in the future if $K_{i}$ values measured under the same condition could be obtained. The $\mathrm{K}_{\mathrm{i}}$ values varied among the drugs. Also, the degree of affinity for the $5-\mathrm{HT}_{1 \mathrm{~B}}$ and $5-\mathrm{HT}_{1 \mathrm{D}}$ receptors was found to vary depending on the drug.

For the present analysis, the drug concentration near the target receptors was considered to be at the same level as that of the unbound drug in plasma. It was previously reported that the $5-\mathrm{HT}_{1 \mathrm{~B}}$ receptor, an action target of triptans, is present in the intra-cranial vessels, while the $5-\mathrm{HT}_{1 \mathrm{D}}$ receptor exists in the trigeminal nerve around the intra-cranial vessels [28]. However, there are no known reports of direct measurements of drug concentration near these receptors. Accordingly, we speculated that a drug unbound from plasma protein may reach the action site by permeation through the vessel wall after being transferred to blood following administration.

The blood-brain barrier (BBB) penetration of triptan differs in each drug. Sumatriptan and naratriptan especially are scarcely passing through $\mathrm{BBB}$ and showing a thin distribution in the central nervous system [20,29]. However, they elicited the same therapeutic effect for migraine as other triptans. Furthermore, Tomita et al. suggested that triptans also acted on $5-\mathrm{HT}_{1 \mathrm{~B} / 1 \mathrm{D}}$ receptors in the trigeminal and dorsal root ganglion cells where $\mathrm{BBB}$ was lacked rather than in the sites with $\mathrm{BBB}$ 

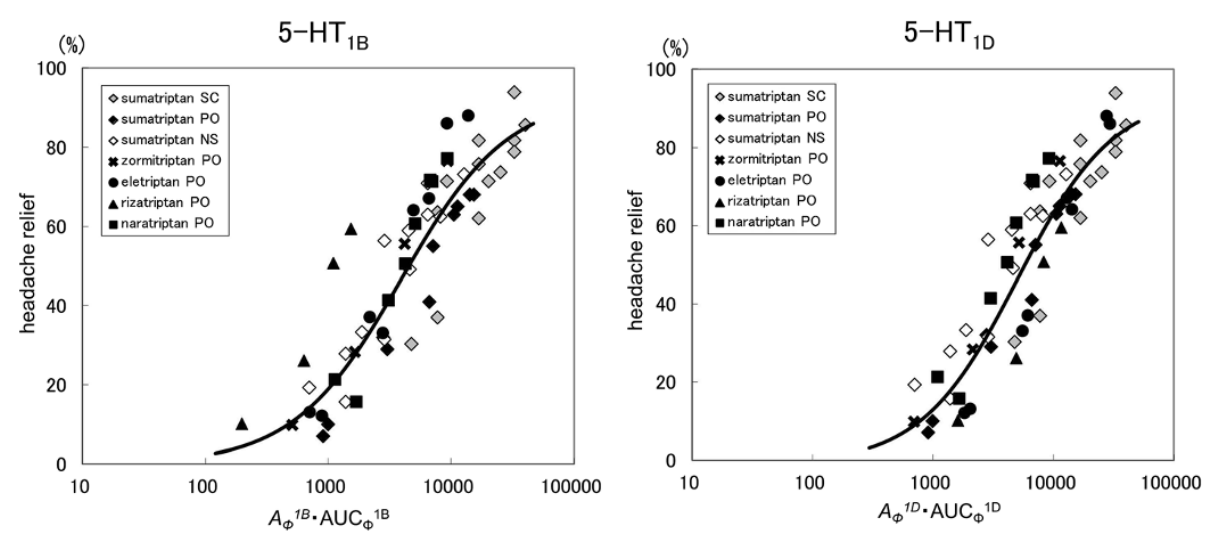

Figure 5 Relationships between $A_{\Phi}{ }^{1 B} \cdot \mathrm{AUC}_{\Phi}{ }^{1 \mathrm{~B}}$ or ${A_{\Phi}}^{1 D} \cdot \mathrm{AUC}_{\Phi}{ }^{1 \mathrm{D}}$ and headache relief rate. (SC: subcutaneous injection, PO: oral tablet, NS: nasal spray, Solid line: Fitting curve).

in the trigeminovascular system [30]. For this reasons, in this study, we have taken into account only vascular permeability of triptans. In future, the target tissue and receptor of triptans become clearer. And if actual measurement drug concentration at the target site is obtained, we will be able to do more accurate analysis in consideration of $\mathrm{BBB}$ penetration.

Using the collected data, changes in receptor occupancy, shown by $\Phi_{1 \mathrm{~B}}$ and $\Phi_{1 \mathrm{D}}$, were calculated on the basis of reported changes in plasma drug concentration. As shown in Figure 1, sumatriptan and naratriptan had nearly the same changes for both the $5-\mathrm{HT}_{1 \mathrm{~B}}$ and $5-\mathrm{HT}_{1 \mathrm{D}}$ receptors, as our results revealed nearly the same $K_{i}$ values for those receptors. Meanwhile, zolmitritan, eletriptan, and rizatriptan demonstrated changes when $\Phi$ was higher for the $5-\mathrm{HT}_{1 \mathrm{D}}$ receptor than for the $5-\mathrm{HT}_{1 \mathrm{~B}}$ receptor, as the affinity for the $5-\mathrm{HT}_{1 \mathrm{D}}$ receptor was greater.

Using reported $C_{\max }$ values, we calculated $\Phi_{\max }{ }^{1 B}$ and $\Phi_{\max }{ }^{1 \mathrm{D}}$. As shown in Table 4 , the $\mathrm{C}_{\max }$ values varied greatly depending on the drug. Meanwhile, as a certain effect was obtained without regard to the kind and dosage form, it was considered difficult to quantitatively predict the clinical effect on the basis of the plasma drug concentration. Our calculations showed that $\Phi_{\max }^{1 \mathrm{~B}}$ and $\Phi_{\max }{ }^{1 \mathrm{D}}$ were relatively high at $32.0-89.4 \%$ and $68.4-96.2 \%$, respectively, suggesting that it is likely that a high occupancy is necessary to attain the clinical effect. Sumatriptan showed

Table 5 Estimated value of $\mathrm{E}_{\max }, \mathrm{EC}_{50}$, and $\gamma$

\begin{tabular}{lll}
\hline Parameter & \multicolumn{2}{l}{ Estimated value \pm S.E. } \\
\cline { 2 - 3 } & $\boldsymbol{A}_{\boldsymbol{\Phi}}{ }^{\mathbf{B}} \cdot \mathbf{A U C}_{\boldsymbol{\Phi}}{ }^{\mathbf{B}}$ & $\boldsymbol{A}_{\boldsymbol{\Phi}}{ }^{\mathbf{D}} \cdot \mathbf{A U C}_{\boldsymbol{\Phi}} \mathbf{1 D}^{\mathbf{D}}$ \\
\hline$E_{\max }$ & $92.5 \pm 9.9$ & $92.5 \pm 8.5$ \\
$\mathrm{EC}_{50}$ & $3529.7 \pm 985.6$ & $4740.0 \pm 995.7$ \\
$Y$ & $0.97 \pm 0.18$ & $1.11 \pm 0.18$ \\
\hline
\end{tabular}

a greater than 3.6-fold difference for $\mathrm{C}_{\max }$ between the injectable $(3 \mathrm{mg})$ and nasal $(20 \mathrm{mg})$ preparations at the usual dose. However, the difference between $\Phi_{\max }{ }^{1 \mathrm{~B}}$ and $\Phi_{\max }{ }^{1 \mathrm{D}}$ was about 1.3-fold, which was not as great as that seen in regard to blood concentration. On the basis of these findings, we considered that $\Phi$ could be quantitatively indicative of the clinical effect, which was difficult to evaluate by using plasma drug concentration. Furthermore, the value for $\Phi$ necessary for the onset of efficacy could be attained in all of the dosage forms. Thus, it is suggested that $\Phi$ might be useful for quantitative evaluation of the clinical efficacy of each dosage form.

We have reported many papers about the relationships between the receptor binding occupancies and clinical effects or adverse reactions in the various kinds of drugs. Among these articles, for benzodiazepines, dopamine $D_{2}$ antagonists, dopamine $\mathrm{D}_{2}$ agonists, and histamine $\mathrm{H}_{1}$ antagonists, we reported that theoretical calculated values reflected the actual values measured by Positron Emission Tomography (PET) [10,31-34]. Also, with regard to other drugs, we suggested that it was possible to analyze the effects of drugs by using theoretical calculated values $[4-7,35]$.

We also examined the relationship between clinical effect and $\Phi$. Data for the time course of clinical effect were mainly extracted from the results of Phase II and III clinical trials performed in Japan. Meanwhile, in pharmacokinetic data mainly obtained in Phase I trials of healthy adults, bioequivalence was shown to be obtained between healthy adults and patients with migraine when a tablet preparation was used [36]. Accordingly, in the present study we used data for our analyses based on the speculation that they were the same as those obtained when tablets were given to patients. In clinical trials of migraine therapeutic agents, headache relief rate at 2 hours after administration is typically used as a major evaluation time point. In the present study, with the time factor taken into 
account, change in headache relief rate was used as a secondary end point.

In our analysis of the relationship with headache relief rate, a different profile was suggested between drug kind or dosage form for $\mathrm{AUC}_{\mathrm{cp}}, \mathrm{AUC}_{\Phi}{ }^{1 \mathrm{~B}}$, and $\mathrm{AUC}_{\Phi}{ }^{1 \mathrm{D}}$, which showed no definite relationship. For the parameter $A_{c p} \cdot \mathrm{AUC}_{\mathrm{cp}}$, in which velocity was taken into consideration, differences were observed among the preparations. However, for the parameters $A_{\Phi}{ }^{1 B} \cdot \mathrm{AUC}_{\Phi}{ }^{1 \mathrm{~B}}$ and $A_{\Phi}{ }^{1 D} \cdot \mathrm{AUC}_{\Phi}{ }^{1 \mathrm{D}}$, for receptor occupancy coupled with velocity, a relationship was observed irrespective of drug kind and dosage form, which could be assimilated into a single line. Moreover, the $5-\mathrm{HT}_{1 \mathrm{D}}$ receptor showed a better correlation coefficient than the $5-\mathrm{HT}_{1 \mathrm{~B}}$ receptor. It was previously reported that the contribution to clinical efficacy varied between the $5-\mathrm{HT}_{1 \mathrm{~B}}$ and $5-\mathrm{HT}_{1 \mathrm{D}}$ receptors [37]. Our findings suggest that the $5-\mathrm{HT}_{1 \mathrm{D}}$ receptor has a greater contribution, though additional study is necessary.

Our findings indicate that is difficult to evaluate the relationship of triptan preparations with clinical efficacy by using only plasma drug concentration. However, that could be evaluated by using receptor occupancy. Furthermore, clinical efficacy might be determined with higher precision by taking into account the rate of receptor binding. Thus, we considered that the parameter $A_{\Phi}{ }^{1 \mathrm{D}} \cdot \mathrm{AUC}_{\Phi}{ }^{1 \mathrm{D}}$ is a useful index for evaluating clinical effect.

It is likely that the clinical efficacy of triptans can not be accurately evaluated by using plasma drug concentration, if a drug such as zolmitriptan with an active metabolite is analyzed only based on the unchanged drug concentration. In light of this, evaluation on the basis of receptor occupancy, which can quantify by taking into consideration the presence of the active metabolite, is considered appropriate.

A previous report [10] suggested that absorption rate should be taken into consideration when examining the clinical efficacy of sumatriptan and the present results support those findings. Moreover, to set a parameter that takes into consideration absorption rate, a prior study [38] investigated that of sumatriptan at the time of initial administration by using $C_{\max } / \mathrm{T}_{\max }$. The values reported in that study were similar to our results. Accordingly, it is considered that our method for taking into consideration velocity might be appropriate.

\section{Conclusions}

We suggest a common index that enables evaluation of the clinical efficacy of triptans irrespective of drug kind and dosage form by using a single line. We concluded that the preparation choice and prediction of clinical effect of an additional dose for appropriately designing an administration plan can be realized by use of a standard curve. Thus, by calculating $A_{\Phi}$ and $\mathrm{AUC}_{\Phi}$ for attaining the full clinical effect, changes in plasma drug concentration can be obtained, making possible an estimation based on drug, dosage form, and dose. Receptor occupancy can be used as a parameter for a common index to evaluate the therapeutic effect. We considered that the present findings provide useful information to support the proper use of triptans. In a future study, we intend to develop a system for clinical application.

\section{Abbreviations \\ 5-HT: 5-hydroxytriptamine; AUC: Area under the curve; $\Phi$ : Receptor occupancy.}

\section{Competing interests}

The authors declare that they have no competing interests.

\section{Authors' contributions}

KT conceptualized and designed the study, acquired and analysis the data, and drafted the manuscript. RT conceptualized and designed the study, acquired and analysis the data, and drafted the manuscript. YS

conceptualized and designed the study. MW conceptualized and designed the study. YK critically revised the manuscript. YY conceptualized and designed the study and critically revised the manuscript. All authors read and approved the final manuscript.

\section{Funding}

No grants or fellowships are supporting the writing of the paper.

\section{Author details}

1Department of Neurology, Tokai University Hachioji Hospital, 1838 Ishikawa-cho, Hachioji, Tokyo 192-0032, Japan. ${ }^{2}$ School of Pharmacy, Tokyo University of Pharmacy and Life Sciences, 1432-1 Horinouchi, Hachioji, Tokyo 192-0392, Japan. ${ }^{3}$ Department of Pharmacy, Tokai University Hachioji

Hospital, 1838 Ishikawa-cho, Hachioji, Tokyo 192-0032, Japan.

Received: 17 September 2014 Accepted: 20 November 2014 Published: 8 December 2014

\section{References}

1. Da Silva AN, Tepper SJ (2012) Acute treatment of migraines. CNS Drugs 26 (10):823-839. doi:10.2165/11635440-000000000-00000

2. Johnston MM, Rapoport AM (2010) Triptans for the management of migraine. Drugs 70(12):1505-1518. doi:10.2165/11537990-000000000-00000

3. Societas Neurologica Japonica and Japanese headache society (2013) Japanese guidelines for the management of primary headache. IGAKU-SHOIN Ltd, Tokyo

4. Yamada Y, Irizuki N, Takayanagi R, Yamamoto K, Sawada Y, Iga T (2003) Pharmacokinetic/pharmacodynamic analysis of anti-hyperprolactinemic effect of terguride based on dopamine $D_{2}$ receptor occupancy. Yakugaku Zasshi 123(4):255-260. PubMed PMID: 12704865

5. Yamada Y, Sugiura M, Higo K, Ozeki T, Takayanagi R, Okuyama K, Yamamoto K, Satoh H, Sawada Y, Iga T (2004) Receptor occupancy theory-based analysis of antiemetic effects and standard doses of 5- $\mathrm{HT}_{3}$ receptor antagonists in cancer patients. Cancer Chemother Pharmacol 54(2):185-190. PubMed PMID: 15168080

6. Takayanagi R, Mizushima H, Ozeki T, Yokoyama H, Iga T, Yamada Y (2007) Analysis of pharmacological effects of drugs used for treatment of urinary disturbance based on anticholinergic and smooth muscle-relaxing effects. Biol Pharm Bull 30(7):1297-1300. PubMed PMID: 17603170

7. Ayuhara H, Takayanagi R, Okuyama K, Yoshimoto K, Ozeki T, Yokoyama H, Yamada Y (2009) Receptor occupancy theory-based analysis of interindividual differences in antiemetic effects of 5- $\mathrm{HT}_{3}$ receptor antagonists. Int J Clin Oncol 14(6):518-524. doi: 10.1007/s10147-009-0912-5

8. Takayanagi R, Tokuoka K, Suzuki Y, Watanabe M, Kitagawa Y, Yamada Y (2012) Analysis of drug efficacy of sumatriptan for acute migraine based on receptor occupancy. Jpn J Headache 39(1):91-97 
9. Sawada Y, Yamada Y, Iga T (1997) Quantitative evaluation of pharmacological effects and adverse effects based on receptor occupancy theory. Yakugaku Zasshi 117(2):65-90. [in Japanese], PubMed PMID: 9084225

10. Ferrari A, Pinetti D, Bertolini A, Coccia C, Sternieri E: (2008) Interindividual variability of oral sumatriptan pharmacokinetics and of clinical response in migraine patients. Eur J Clin Pharmacol 64:489-495. doi: 10.1007/s00228007-0443-9

11. IMIGRAN Injection/ Kit Subcutaneous Injection Product Information (2008) [in Japanese] Pharmaceuticals and Medical Devices Agency, Tokyo. http//wwww.info.pmda.go.jp/go/pack/2160402G1026_1_04/. Accessed 1 Jun 2014

12. IMIGRAN Tablets Product Information (2007) [in Japanese] Pharmaceuticals and Medical Devices Agency, Tokyo. http://www.info.pmda.go.jp/go/pack/ 2160003F1022 1 06/. Accessed 1 Jun 2014

13. IMIGRAN Nasal Spray Product Information (2003) [in Japanese] Pharmaceuticals and Medical Devices Agency, Tokyo. http://www.info.pmda. go.jp/go/pack/2160700Q1027_1_05/. Accessed 1 Jun 2014

14. ZOMIG Tablets Product Information (2006) [in Japanese] Pharmaceuticals and Medical Devices Agency, Tokyo. http://www.info.pmda.go.jp/go/pack/ 2160004F1027_1_11/. Accessed 1 Jun 2014

15. Dixon R, Warrander A (1997) The clinical pharmacokinetics of zolmitriptan. Cephalalgia Suppl 18:15-20. PubMed PMID: 9399013

16. Summary basis of approval of ZOMIG (2005) [in Japanese]Pharmaceuticals and Medical Devices Agency, Tokyo. http://www.info.pmda.go.jp/shinyaku/ P200100027/index.html. Accessed 1 Jun 2014

17. RELPAX Tablets Product Information (2003) [in Japanese] Pharmaceuticals and Medical Devices Agency, Tokyo. http://www.info.pmda.go.jp/go/pack/ 2160005F1021_2_03/. Accessed 1 Jun 2014

18. MAXALT Tablets/RPD Tablets Product Information (2006) [in Japanese] Pharmaceuticals and Medical Devices Agency, Tokyo. http://www.info.pmda. go.jp/go/pack/2160006F1026_2_10/. Accessed 1 Jun 2014

19. Napier C, Stewart M, Melrose H, Hopkins B, McHarg A, Wallis R (1999) Characterisation of the $5-\mathrm{HT}$ receptor binding profile of eletriptan and kinetics of $[3 \mathrm{H}]$ eletriptan binding at human $5-\mathrm{HT}_{1 \mathrm{~B}}$ and $5-\mathrm{HT}_{1 \mathrm{D}}$ receptors. Eur J Pharmacol 368(2-3):259-268. doi:10.1016/S0014-2999(99)00026-6

20. AMERGE Tablets Product Information (2008) [in Japanese] Pharmaceuticals and Medical Devices Agency, Tokyo. http://www.info.pmda.go.jp/go/pack/ 2160007F1020_1_04/. Accessed 1 Jun 2014

21. Tazaki Y, Sakai F, Tashiro K, Hirai S, Maruyama S, Gotoh F, Takahashi A, Takahashi K, Araki S (1993) Study on clinical usefulness of SN-308 (Sumatriptan) subcutaneous injection in migraine -dose finding study by envelope method. J Clin Ther Med 9(5):1077-1093 [in Japanese]

22. Sakai F, Fukuuchi Y, Matsumoto K, Miyazaki H, Nakashima K, Ohashi K (2000) SN-308(Sumatriptan) subcutaneous injection phase III study - a doubleblind, placebo-controlled, parallel-group study in migraine patients. J Clin Ther Med 16(3):283-300 [in Japanese]

23. Summary basis of approval of IMIGRAN Tablets (2001) [in Japanese] Pharmaceuticals and Medical Devices Agency, Tokyo. http://www.info.pmda. go.jp/shinyaku/P200100028/index.html. Accessed 1 Jun 2014

24. Summary basis of approval of IMIGRAN Nasal Spray (2003) [in Japanese] Pharmaceuticals and Medical Devices Agency, Tokyo. http://www.info.pmda. go.jp/shinyaku/P200300008/index.html. Accessed 1 Jun 2014

25. Summary basis of approval of RELPAX Tablets (2002) [in Japanese] Pharmaceuticals and Medical Devices Agency, Tokyo. http://www.info.pmda. go.jp/shinyaku/P200200017/index.html. Accessed 1 Jun 2014

26. Summary basis of approval of MAXALT Tablets/RPD Tablets (2003) [in Japanese] Pharmaceuticals and Medical Devices Agency, Tokyo. http://www.info.pmda.go.jp/shinyaku/P200300017/index.html. Accessed 1 Jun 2014

27. Summary basis of approval of AMERGE Tablets (2008) [in Japanese] Pharmaceuticals and Medical Devices Agency, Tokyo. http://www.info.pmda. go.jp/shinyaku/P200800004/index.html. Accessed 1 Jun 2014

28. Goadsby PJ (2000) The pharmacology of headache. Prog Neurobiol 62(5):509-525. doi: 10.1016/S0301-0082(00)00010-1

29. Perry CM, Markham A (1998) Sumatriptan. An updated review of its use in migraine. Drugs 55(6):889-922. PubMed PMID: 9617601

30. Tomita M, Suzuki N, Sakai F (2002) The distribution of 5- $\mathrm{HT}_{1 \mathrm{~B}}$ receptors and the effect of anti-migraine drugs triptan in trigeminovascular system of the rat. Kitasato Med 2002(32):173-178 [in Japanese]

31. Ito K, Yamada Y, Nakamura K, Sawada Y, Iga T (1993) Classification of benzodiazepine hypnotics in humans based on receptor occupancy theory. J Pharmacokinet Biopharm 21(1):31-41. PubMed PMID: 8410682
32. Ito K, Asakura A, Yamada Y, Nakamura K, Sawada Y, Iga T (1997) Prediction of the therapeutic dose for benzodiazepine anxiolytics based on receptor occupancy theory. Biopharm Drug Dispos 18(4):293-303. doi:10.1002/(SICI) 1099-081X(199705)18:4<293::AID-BDD24>3.0.CO;2-B

33. Yamada Y, Ohno Y, Nakashima Y, Fukuda M, Takayanagi R, Sato H, Tsuchiya F, Sawada Y, Iga T (2002) Prediction and assessment of extrapyramidal side effects induced by risperidone based on dopamine $D_{2}$ receptor occupancy. Synapse 46(1):32-37. doi:10.1002/syn.10111

34. Atsumi M, Kawakami J, Sugiyama E, Kotaki H, Sawada Y, Sato H, Yamada Y, Iga T (2003) Pharmacokinetic and pharmacodynamic analyses, based on dopamine $\mathrm{D}_{2}$-receptor occupancy of bromocriptine, of bromocriptine-induced contralateral rotations in unilaterally 6-ohda-lesioned rats. Synapse 50(2):110-116. doi: 10.1002/syn.10248

35. Yamada Y, Shibuya F, Hamada J, Sawada Y, Iga T (1995) Prediction of sleep disorders induced by $\beta$-adrenergic receptor blocking agents based on receptor occupancy. J Pharmacokinet Biopharm 23(2):131-145. PubMed PMID: 8719233

36. Fuseau E, Petricoul O, Sabin A, Pereira A, O'Quinn S, Thein S, Leibowitz M, Purdon H, McNeal S, Salonen R, Metz A, Coates P (2001) Effect of encapsulation on absorption of sumatriptan tablets: data from healthy volunteers and patients during a migraine. Clin Ther 23(2):242-251. doi:10.1016/S0149-2918(01)80006-0

37. De Vries P, Villalon CM, Saxena PR (1999) Pharmacological aspects of experimental headache models in relation to acute antimigraine therapy. Eur J Pharmacol 375(1-3):61-74. doi:10.1016/S0014-2999(99)00197-1

38. Fox AW (2004) Onset of effect of 5-HT $1 \mathrm{~B} / 1 \mathrm{D}$ agonists: a model with pharmacokinetic validation. Headache 44:142-147. doi:10.1111/j.15264610.2004.04030.x

doi:10.1186/1129-2377-15-85

Cite this article as: Tokuoka et al:: Theory-based analysis of clinical efficacy of triptans using receptor occupancy. The Journal of Headache and Pain 2014 15:85.

\section{Submit your manuscript to a SpringerOpen ${ }^{\circ}$ journal and benefit from:}

- Convenient online submission

- Rigorous peer review

- Immediate publication on acceptance

- Open access: articles freely available online

- High visibility within the field

- Retaining the copyright to your article

Submit your next manuscript at $>$ springeropen.com 